\title{
A FILOSOFIA DA LINGUAGEM DE V. VOLOSHINOV E O CONCEITO DE IDEOLOGIA
}

Claudiana NARZETTI ${ }^{*}$

- RESUMO: Este trabalho trata da concepção de ideologia que atravessa e constitui a filosofia da linguagem de V. Voloshinov, um dos membros do Círculo de Bakhtin. Ele tem por objetivo lançar novas luzes sobre alguns pontos complexos e delicados da concepção global de ideologia sustentada por Voloshinov, acerca dos quais os estudiosos do grupo russo ainda não chegaram a uma definição ou a um consenso. A exposição se organiza em torno de três pontos: 1) a ideologia enquanto elemento estrutural da sociedade; 2) a ideologia enquanto campo dos signos; 3) a ideologia enquanto representações do real. A reflexão centra-se nas formulações nas quais Voloshinov avança com base naquilo que suas fontes teóricas já haviam proposto, principalmente no que tange à articulação da ideologia com a linguagem. Espera-se que o trabalho possa chamar a atenção para a importância de uma recuperação desse conceito e de sua articulação com outros formulados ao longo da trajetória teórica do Círculo de Bakhtin, como o de diálogo, com vistas a um enriquecimento cada vez maior dos trabalhos de análise do discurso de orientação bakhtiniana.

- PALAVRAS-CHAVE: Ideologia. Voloshinov. Filosofia da linguagem. Círculo de Bakhtin.

\section{Considerações iniciais}

Uma reflexão sobre o conceito de ideologia que atravessa as formulações do Círculo de Bakhtin acerca da linguagem em geral e da linguagem literária em particular não pode ser conduzida sem que se toque em um ponto muito delicado relativo à história do grupo russo - o problema da autoria de algumas obras de seus membros. Entendemos que seja assim porque há uma discrepância no que tange à importância desse conceito nas diversas obras do grupo - enquanto ele é constitutivo das formulações de algumas obras, é marginal em outras. A nosso ver, essa discrepância se explica mais adequadamente se aceitamos que Bakhtin não é o autor de todas as obras publicadas com a assinatura de outros membros do Círculo, como Voloshinov e Medvedev, e se aceitamos que estes últimos tinham uma preocupação muito maior que o primeiro em relação ao referido conceito. Sendo assim, neste trabalho, partimos do pressuposto de que Voloshinov é o

* Universidade do Estado do Amazonas (UEA)/Escola Normal Superior. Membro do SLOVO (Grupo de Estudos do Discurso). Manaus - AM - Brasil. 69050-010- cn.narzetti@uol.com.br 
autor de Marxismo e filosofia da linguagem, e é sobre sua concepção acerca do conceito de ideologia que refletiremos. ${ }^{1}$

Voloshinov anuncia, desde o princípio de sua obra Marxismo e filosofia da linguagem, que sua tarefa é propor uma filosofia da linguagem de base marxista, concebida pelo autor como diretamente ligada a uma teoria das ideologias (tanto dependendo dela quanto fazendo-a avançar). Conforme Voloshinov (1979, p.25): "Um dos problemas fundamentais do marxismo, o das relações entre a infraestrutura e as superestruturas, acha-se intimamente ligado, em muitos de seus principais aspectos, aos problemas da filosofia da linguagem." Essa filosofia da linguagem poderia elucidar os problemas relacionados àquilo que a teoria marxista descreveu como as relações de determinação da superestrutura de uma sociedade pela sua base econômica. Um problema específico desse campo de reflexões, ao qual o autor russo mais dedica seu esforço teórico, é o da linguagem e sua função/ funcionamento dentro do quadro das relações sociais e das mudanças históricas.

Portanto, as reflexões de Voloshinov têm um ponto de vista muito específico e bem determinado - o da teoria marxista; este é o campo das questões, ou seja, aquele que gera as questões e os problemas. É ele que se busca desenvolver. Ainda que as soluções apresentadas pelo filósofo da linguagem sejam formuladas com base também em outras perspectivas, heterogêneas à marxista, ${ }^{2}$ isso não significa absolutamente que se trate de um "marxismo de vitrine" (CLARK; HOLQUIST, 1998) ou um mero emprego de "palavras carregadas", como ideologia, classes sociais, infra e superestrutura, etc. A nosso ver, qualquer estudo ou discussão sobre o pensamento de um autor e sua filiação/suas heranças, deve ter como ponto de partida a sua problemática e não um simples levantamento das "palavras" que ele utiliza. O fato de diferentes pensadores utilizarem uma mesma palavra não é garantia de que estejam falando da mesma coisa, simplesmente porque, como nos ensina Canguilhem (1972), uma palavra não é um conceito e um conceito não é uma palavra.

Partindo desses pressupostos, nosso objetivo aqui é explorar a concepção de ideologia que atravessa as reflexões de Voloshinov, elas mesmas voltadas ao desenvolvimento desse conceito. Não há uma única definição do termo ideologia nas reflexões de Voloshinov - há diversas definições, todas elas complementares, elaboradas de um ponto de vista distinto. Enfocaremos, assim, três dessas

\footnotetext{
Vale, entretanto, destacar que a reflexão de Voloshinov é pautada em todo o conjunto das reflexões que marcam os trabalhos do Círculo de Bakhtin, atestando a intensa troca dialógica entre seus membros.

2 Conforme Tihanov (2000) e outros estudiosos do Círculo de Bakhtin, o grupo russo (Bakhtin e Voloshinov, principalmente) tinha um embasamento em correntes de pensamento como o neo-kantismo e a filosofia da vida. Entendemos que os estudos realizados são uma importante contribuição para o problema das heranças teóricas do grupo, mas que um estudo de fôlego precisa ainda ser feito para evidenciar em quais pontos cada uma dessas correntes são, de fato, constitutivas das formulações mais caracterizadoras do pensamento bakhtiniano.
} 
definições: a ideologia enquanto elemento estrutural da sociedade; a ideologia enquanto campo dos signos; a ideologia enquanto representações do real. A exposição se organiza sempre em torno da apresentação das formulações acerca do conceito de ideologia que Voloshinov retoma de suas fontes teóricas e das formulações próprias de Voloshinov, ou seja, os pontos em que ele avança além de suas fontes, lançando problemas novos a partir de novos pontos de vista. Ao discutirmos essas definições, as suas filiações e os avanços de Voloshinov em relação a elas, tentaremos trazer à tona certos problemas relativos ao tema, que, não diretamente discutidos pelo autor russo, estão estreitamente implicados em suas reflexões. Valemo-nos, para tal empresa, das conclusões acerca desse problema a que chegaram importantes estudiosos do grupo bakhtiniano, tais como Tihanov (2000), Ponzio (2008), Faraco (2006) e Grillo (2008).

\section{Ideologia - elemento estrutural da sociedade}

Para Voloshinov, em primeiro lugar, a ideologia é um elemento da estrutura da formação social, uma das partes em que se subdivide a sua superestrutura, que é determinada, ainda que indiretamente, pela base econômica. "A realidade ideológica é uma superestrutura situada imediatamente acima da base econômica." (VOLOSHINOV, 1979, p.22). Pode ser entendida, segundo Faraco (2006, p.46), como "[...] o universo dos produtos do 'espírito' humano."; as "formas da consciência social"; " "...] o universo que engloba a arte, a ciência, a filosofia, o direito, a religião, a ética, a política, ou seja, todas as manifestações superestruturais." Sendo assim, a ideologia, para o autor russo, não é um bloco monolítico, mas uma realidade plural. Ela estaria dividida entre os sistemas ideológicos constituídos e a ideologia do cotidiano. Para entendermos essa formulação de Voloshinov, é necessário que tratemos primeiramente do que as suas referências avançaram em relação a este ponto.

Conforme demonstraram Tihanov (2000) e Grillo (2008), Voloshinov segue as elaborações de dois estudiosos e difusores do marxismo na URSS: Georgi Plekhanov e Nicolai Bukharin. Estes formavam, juntamente com Lênin, as principais referências teóricas daqueles que trabalhavam no interior do campo marxista. Segundo Tihanov (2000), ainda que Voloshinov não mencione explicitamente Bukharin, como o faz com Plekhanov, o autor tem em seu horizonte também as reflexões de Bukharin. Esses estudiosos retomaram as formulações iniciais fornecidas por Marx em algumas de suas obras, dando-lhes algum desenvolvimento e são elas que Voloshinov retoma para repensá-las/desenvolvêlas.

Plekhanov, em sua obra Os princípios fundamentais do marxismo, de 1908, sustenta que Marx e Engels deslocam a tese de Feuerbach de que a arte, a religião, 
a filosofia e a ciência (os fenômenos superestruturais) seriam manifestações ou revelações da essência humana, afirmando que esses fenômenos têm, na verdade, uma causa material, a qual se encontra na estrutura econômica de uma sociedade. Esse deslocamento teria como base uma filosofia materialista. Retomando essa questão, Plekhanov (1978, p.62) lança a seguinte proposição:

Se nos propuséssemos a expor brevemente a concepção de Marx e Engels, sobre a relação entre a célebre "base" e a não menos célebre "superestrutura", chegaríamos a isto:

1. Estados das forças produtivas;

2. relações econômicas condicionadas por estas forças;

3. regime sócio-político, edificado sobre uma "base" econômica dada;

4. psicologia do homem social, determinada, em parte, diretamente pela economia, em parte por todo o regime sócio-político edificado sobre ela;

5. ideologias diversas refletindo esta psicologia.

Pode-se entender desse esquema que a superestrutura ideológica é dividida em duas partes constituídas pela "psicologia do homem social" e pelas "ideologias diversas". A psicologia social seria determinada pela economia e pelo regime sócio-político, enquanto as ideologias diversas a refletiriam, tendo nela a sua "raiz comum". Plekhanov, ao defender que as ideologias têm sua raiz, sua origem, na psicologia da época, mostra bastante preocupação em explorar não somente as formas de ação recíproca entre as forças sociais, mas também a origem das mesmas. Por isso, aqui ele busca a origem das ideologias, colocando-a no campo da psicologia social. Já esta última estaria intimamente ligada às relações entre os homens na produção - quando estas se transformassem, também transformarse-ia o estado psíquico humano.

Vale lembrar que a intenção de Plekhanov, ao apresentar esse esquema, é ilustrar o princípio marxista da determinação principal pela economia sobre todos os níveis da formação social, mas visa também a evidenciar que há formas de ação recíprocas desses níveis entre si. Sendo assim, as relações na produção teriam ação sobre a psicologia social e esta, sobre as ideologias diversas.

O desenvolvimento da ação recíproca dos níveis da formação social, em especial dos dois subníveis da ideologia, parece ter avançado um pouco mais com as reflexões de Bukharin (no que é seguido por Voloshinov, como veremos). Em seu Tratado de Materialismo Histórico, de 1921, Bukharin segue a proposição de Plekhanov acima referida acerca da psicologia social e da ideologia.

Começando sua explanação pelo conceito de superestrutura, Bukharin (1970) afirma que esta diz respeito a qualquer forma de fenômenos sociais que se eleva acima da base econômica, sendo, portanto, "bastante complexa na sua 'estrutura' interior" (BUKHARIN, 1970, p.243), uma vez que conteria objetos materiais, organizações humanas, combinações de ideias e imagens sistematizadas, ideias e 
sentimentos difusos, não sistematizados, etc. Todos esses elementos, organizados em conjuntos, dizem respeito: à estrutura política e social da sociedade; à ideologia social - "[...] os costumes, as leis e a moral [...]; a ciência e a filosofia; a religião, a arte, e enfim a linguagem [...]" (BUKHARIN, 1970, p.167); e, finalmente, à psicologia social - "[...] aquilo que existe de não sistematizado ou pouco sistematizado na alma social, os sentimentos, os pensamentos e as disposições gerais que fazem o espírito de uma sociedade, duma classe, dum grupo, de uma profissão etc." (BUKHARIN, 1970, p.243-244).

Segundo o autor, o que distingue a ideologia e a psicologia social seria o seu grau de sistematização. A psicologia social, segundo a passagem acima citada, diz respeito às "ideias correntes" (pensamentos, sentimentos, desejos, gostos, julgamentos) acerca dos mais variados objetos que compõem a vida social, as quais são fragmentárias, dispersas e desordenadas.

Numa sociedade, segundo Bukharin (1970), não há uma única psicologia social, mas várias, visto que ela se constitui como um efeito da divisão da sociedade em classes (cada classe elabora sua psicologia em conformidade com suas condições de existência, com suas relações na produção, com seu lugar na produção etc.). No entanto, em cada época, há uma tendência dominante nos pensamentos, nos sentimentos, ou seja, há "uma psicologia dominante" que "colora" toda a vida social. Esta última é a psicologia da classe dominante, que englobaria "caracteres psicológicos gerais" e "caracteres psicológicos exclusivos" da classe dominante.

A psicologia social é determinada também, ainda que de modo secundário, pela existência, no interior das classes, de grupos ligados a profissões, atividades e ofícios: cada grupo tem traços psicológicos próprios, os quais podem se tornar constitutivos da psicologia social de uma época. Essa psicologia dos grupos, como veremos, está intimamente ligada à constituição das ideologias.

Enquanto a psicologia social tem sua emergência ligada à existência das classes sociais (refletem suas condições de vida, representam suas ideias, sentimentos e opiniões acerca da vida social, etc.), a ideologia tem sua emergência ligada à separação do trabalho manual e do trabalho intelectual - ela existe porque uma classe ou uma fração de classe dedica-se exclusivamente à produção intelectual, podendo sistematizar, organizar e ajustar os pensamentos, sentimentos, ideias, costumes, normas de conduta, existentes em forma "fluida" na psicologia social. Segundo Bukharin (1970), somente quando uma sociedade alcança um determinado estágio do desenvolvimento das forças produtivas, com a simultânea divisão social e técnica do trabalho, é que se dá o "aparecimento do trabalho puramente ideológico" (BUKHARIN, 1970, p.255). Este último acaba também seguindo a lógica da divisão do trabalho social - a ideologia divide-se em ramos como o direito, as ciências, as artes, a filosofia e a religião, e cada um 
desses ramos adquire novas ramificações - a ciência e a arte, por exemplo, com suas diferentes especialidades.

Bukharin (1970) concebe as ideologias como um "produto espiritual" que resulta de um trabalho social, ainda que não da produção material em si mesma. Os processos ideológicos podem ser tomados como "[...] uma forma determinada de trabalho. Este trabalho não é a produção material. Não é nem mesmo uma parte dela. [...] ele surge da produção material e dela se destaca para formar ramos especiais da atividade social." (BUKHARIN, 1970, p.255). Parece-nos que, na concepção de Bukharin da ideologia como um produto espiritual, pode-se encontrar uma réstia de idealismo. A perspectiva materialista de Bukharin o conduz a conceber a ideologia como determinada pela estrutura econômica da sociedade, pela produção material; mas não permite que ele defina os próprios produtos ideológicos como sendo materiais, como tendo uma existência material. Voloshinov, ao contrário, como veremos, acentua o caráter material dos signos ideológicos.

Quanto às relações entre ambas, Bukharin (1970) segue a tese de Plekhanov de que as ideologias refletem a psicologia social: "A psicologia social é de certa maneira um reservatório para a ideologia." (BUKHARIN, 1970, p.253). Segundo o autor, "[...] existe um processo contínuo de concretização, de solidificação da psicologia social." (BUKHARIN, 1970, p.253), por meio da ideologia. "Por isso, toda variação da psicologia social é acompanhada de uma variação da ideologia social." (BUKHARIN, 1970, p.253).

Segundo Tihanov (2000), Bukharin, ao propor que mudanças na psicologia social determinam mudanças na ideologia, teria desenhado uma "conexão de mão única" entre psicologia e ideologia, já que apenas aquela acarreta efeitos nesta. Voloshinov, debruçando-se sobre essas reflexões e desenvolvendo-as, demonstra que também a ideologia exerce efeitos sobre a psicologia social (que ele chama de ideologia do cotidiano). Voltaremos a isso.

Como se daria, no ver de Bukharin, essa relação da ideologia com a psicologia social? Vimos acima que há uma psicologia derivada dos grupos sociais constituídos em função de profissões, ofícios etc. Esta, segundo o autor, tem uma relação direta com a constituição das diferentes ideologias existentes. Veja-se a tese de Bukharin (1970, p.252, grifo nosso): "Formam-se tipos profissionais cujas particularidades mentais decorrem diretamente do gênero de ocupação e cuja psicologia dá origem a uma ideologia especial." Com essa tese, Bukharin enfatiza que o trabalho intelectual de certos indivíduos pertencentes a certos grupos profissionais no interior das classes sistematiza essa psicologia gerada mais ou menos espontaneamente, sistematização essa que forma as ideologias existentes. Também deixa ver que, para ele, a divisão da ideologia em regiões está relacionada às profissões existentes, isto é, à divisão técnica do 
trabalho intelectual. Essa hipótese fica mais evidente quando temos em mente que, para Bukharin, as ideologias tiveram como condição de sua constituição a divisão social do trabalho, em que algumas classes puderam dedicar-se exclusivamente ao trabalho intelectual. Levando em conta que, comumente, são as classes dominantes ou os seus representantes que podem dedicar-se ao trabalho intelectual, pode-se afirmar que aí se encontram os motivos de a perspectiva da classe dominante ser dominante na ideologia. Nas formas de trabalho ideológico se verifica, assim como no trabalho de produção material, a existência de hierarquias, onde, no cume, estão os principais, os detentores dos "meios espirituais da produção" etc. Assim, as classes dirigentes ou dominantes têm o monopólio do saber e de todos os produtos da ideologia - elas os produzem, os divulgam e também impedem sua divulgação para aqueles que são considerados indignos de seu conhecimento, usufruto etc.

Assim, a distinção proposta por Voloshinov entre sistemas ideológicos constituídos e ideologia do cotidiano assenta nas formulações e distinções de Plekhanov e de Bukharin sobre a ideologia ou ideologia social e a psicologia social. Segundo Voloshinov (1979, p.26), essas duas instâncias são "qualitativamente diferenciadas" e "[...] dotadas de um conjunto de regras específicas e de um caráter próprio."

Os sistemas ideológicos constituídos correspondem às "esferas da criação ideológica" - a religião, a ciência, a arte, a moral etc. Como o próprio nome indica, esses campos caracterizam-se por serem os mais fortemente sistematizados. Para Voloshinov, além disso, mesmo uma esfera ideológica dada não se apresenta como um conjunto único e indivisível de elementos, mas como um conjunto de elementos com dada autonomia, sendo que cada um deles pode ser estudado em si mesmo e em relação com os outros elementos dessa esfera. O romance, por exemplo, enquanto elemento da esfera literária, pode ser estudado, segundo o autor russo, em seus elementos - sua composição, seu estilo, etc. e/ou em sua relação com outros elementos da literatura, como a poesia. É por isso que, para Voloshinov, uma dada mudança, um dado acontecimento, na esfera literária (como em qualquer esfera) não pode ser explicado por meio de uma remissão a dada mudança ou acontecimento na infraestrutura da sociedade - uma mudança nessa esfera pode estar relacionada com uma mudança na economia, mas ela também se relaciona com outras mudanças ocorridas na própria esfera, e elas devem ser contempladas.

Essa posição de Voloshinov, segundo Tihanov (2000), relaciona-se com o fato de que o autor russo perseguia o problema das leis gerais que governam a emergência e os funcionamentos de uma ideologia, mas sempre a partir de uma perspectiva que, ao mesmo tempo, rejeitava análises mecanicistas e adotava uma análise dialética da evolução social. 
O próprio Voloshinov (1979, p.25) destaca: "A esfera de aplicação da categoria da causalidade mecanicista é extremamente limitada [...]. Está fora de questão, a fortiori, aplicar esta categoria inerte aos problemas fundamentais do materialismo histórico ou a qualquer ciência das ideologias."

O esclarecimento feito por Tihanov (2000) coincide com o de Ponzio (2008, p.113):

Todo elemento ideológico tem que ser considerado no campo ideológico especial ao qual pertence e que possui suas leis específicas. Portanto, segundo Bakhtin [/Voloshinov] não pode haver nenhum valor cognoscitivo em estabelecer uma conexão direta entre estruturas econômico-sociais e um certo fato superestrutural, quando este último se considera separado do campo sígnico-ideológico específico ao qual pertence.

Já a ideologia do cotidiano é concebida por Voloshinov como a instância mais próxima das relações de produção e mais diretamente afetada por ela. Para esse autor, ela diz respeito ao discurso interior e exterior acerca da vida cotidiana e é um domínio de pouca ou nenhuma sistematização.

Chamaremos a totalidade da atividade mental centrada sobre a vida cotidiana, assim como a expressão que a ela se liga, ideologia do cotidiano, para distingui-la dos sistemas ideológicos constituídos, tais como a arte, a moral, o direito, etc. A ideologia do cotidiano constitui o domínio da palavra interior e exterior desordenada e não fixada num sistema, que acompanha cada um dos nossos atos ou gestos e cada um dos nossos estados de consciência. [...] a ideologia do cotidiano corresponde, no essencial, àquilo que se designa, na literatura marxista, sob o nome de "psicologia social". (VOLOSHINOV, 1979, p.104, grifo nosso).

Voloshinov (1979), justificando o uso do termo "ideologia do cotidiano", explica que o termo "psicologia social" empregado por seus mestres poderia sugerir que os conteúdos ideológicos tivessem uma base psicológica/individual, enquanto o termo "ideologia do cotidiano" realçaria a natureza social de tais conteúdos. Segundo Tihanov (2000), Voloshinov, ao cunhar esse termo, acentua a natureza comum entre os sistemas ideológicos constituídos e a ideologia do cotidiano.

É na descrição do funcionamento e da natureza da ideologia do cotidiano que Voloshinov avança em relação a Plekhanov e a Bukharin, elaborando seu próprio ponto de vista. A reflexão acerca desse nível da ideologia pode, conforme Voloshinov, fornecer elementos importantes para a explicação do modo como a base econômica determina a superestrutura de uma sociedade. O ponto de vista da interação verbal é a perspectiva própria de Voloshinov para elucidar essa questão. 
Conforme Voloshinov, a ideologia do cotidiano materializa-se sob a forma da interação verbal. Ela é inteiramente exteriorizada (não é algo interior e/ou do domínio das ideias) na palavra, no gesto, no ato. Com a seguinte afirmação, Voloshinov (1979, p.27), reafirma a sua perspectiva particular ao tratar das ideologias - a da linguagem:

O que chamamos de psicologia do corpo social e que constitui, segundo a teoria de Plekhanov e da maioria dos marxistas, uma espécie de elo de ligação entre a estrutura sócio-política e a ideologia no sentido estrito do termo (ciência, arte, etc.), realiza-se, materializa-se, sob a forma de interação verbal. Se considerada fora deste processo real de comunicação e de interação verbal (ou, mais genericamente, semiótica), a psicologia do corpo social se transforma num conceito metafísico ou mítico (a "alma coletiva", "o inconsciente coletivo", "o espírito do povo" etc.).

Há, segundo Voloshinov, determinadas formas de interação verbal e determinados gêneros discursivos que são ligados à ideologia do cotidiano as conversas de corredor; as trocas de opinião no teatro; as reuniões sociais; a conversa diária sobre os acontecimentos da vida; o discurso interior. Essas formas de interação social e/ou gêneros discursivos manifestam essa ideologia. Ou seja, há uma série de tipos de interação verbal e de gêneros do discurso que são próprios da ideologia do cotidiano, os quais se distinguem dos que são próprios das esferas ideológicas sistematizadas. Por exemplo, uma conferência científica é um tipo de interação verbal/gênero do discurso pertencente especificamente à esfera científica; a conferência não é um gênero da ideologia do cotidiano. Por outro lado, os gêneros das esferas sistematizadas são sempre transformações desses gêneros nascidos na esfera da vida cotidiana.

A ideologia do cotidiano é o lugar de onde emergem e se acumulam mudanças, é o lugar da criação ideológica ininterrupta. Ela é mais flexível, é mais móvel, muda mais constantemente do que as ideologias constituídas. Nela, as mudanças sociais podem repercutir mais rapidamente. Na ideologia do cotidiano, segundo Voloshinov (1979, p.106), "[...] se acumulam as energias criadoras com cujo auxílio se efetuam as revisões parciais ou totais dos sistemas ideológicos." A primeira expressão e a primeira elaboração ideológica das mudanças sociais se dariam no nível da ideologia do cotidiano.

Sendo assim, para Voloshinov, os sistemas ideológicos constituídos e a ideologia do cotidiano mantêm relações dialéticas. Os objetos surgidos na ideologia do cotidiano constituem o material sobre o qual trabalham os sistemas ideológicos visando a sua sistematização, estabilização e acabamento. Por seu turno, a ideologia do cotidiano, recebendo de volta esses objetos sistematizados e acabados, é por eles determinada em algum grau. No entanto, esta última 
também atua como o lugar onde esses objetos são continuamente testados e avaliados, onde eles estabelecem vínculos com a consciência dos indivíduos. Segundo Tihanov (2000), com essa proposição acerca dos efeitos das ideologias na ideologia do cotidiano, Voloshinov avança em relação a Bukharin, estabelecendo uma relação de mão dupla entre esses dois níveis.

Para alguns estudiosos do Círculo de Bakhtin, essa tese de Voloshinov acerca da relação dialética entre as duas instâncias da ideologia é formulada sobre certos pressupostos da filosofia da vida. Segundo Tihanov (2000, p.89), a partição binária da superestrutura em uma região em constante mudança e em outra que não se move e não subsiste por si mesma "segue estritamente a visão de cultura da filosofia da vida, especialmente Simmel", em que as forças de criação e de crescimento estão em conflito com as de consolidação. Segundo Tchougounnikov (2007), o próprio conceito de ideologia do cotidiano remeteria ao conceito de vida. Essa corrente filosófica "[...] busca apreender a 'vida' como um dado primeiro, como um processo orgânico integral que precede a divisão entre matéria e espírito, enquanto uma totalidade inacessível à razão e aos instrumentos conceituais das ciências positivas." (TCHOUGOUNNIKOV, 2007, p.4). A ideologia do cotidiano seria essa ideologia que nasce e se desenvolve na vida, sendo concebida como processo orgânico integral, como totalidade, como heterogeneidade pura, como temporalidades diversas, que, enquanto tal, não pode ser sistematizada nas ideologias propriamente ditas, mas apenas a partir de uma divisão dessa totalidade em campos e objetos específicos. A totalidade da vida, da ideologia do cotidiano, é sistematizada nas esferas da religião, da estética, da ciência, da moral, que tratam, respectivamente, de apenas uma parte dessa totalidade.

Para Voloshinov (1979), a ideologia do cotidiano é, portanto, o elo entre a infraestrutura econômica e os sistemas ideológicos constituídos. Mas como é possível essa ligação entre as duas instâncias ideológicas e, ainda, entre elas e a infraestrutura? Essa ligação se dá por meio da linguagem verbal, dos signos verbais, pois estes são onipresentes na sociedade e neles se expressam as menores mudanças sociais.

\section{Ideologia - o campo dos signos}

O avanço mais significativo de Voloshinov em relação a Plekhanov e a Bukharin, conforme a maioria de seus estudiosos, reside em sua concepção essencialmente semiótica da ideologia: "Tudo que é ideológico possui valor semiótico"; a ideologia é o domínio por excelência dos signos: "O domínio do ideológico coincide com o domínio dos signos: são mutuamente correspondentes." (VOLOSHINOV, 1979, p.18). Os signos são os elementos constitutivos da ideologia, e assim se justifica a posição segundo a qual uma teoria da ideologia dependa necessariamente de uma filosofia da linguagem, concebida como filosofia do signo ideológico. 
Os signos ideológicos, conforme o autor, são dos mais variados tipos, e pode-se dividi-los em verbais e não verbais. Essa variedade de signos se deve à variedade de esferas da criação ideológica: cada uma dessas esferas possui um sistema de signos que lhe é específico e aí preenche certas funções: estética, científica, religiosa etc. Por exemplo, a esfera científica trabalha com as fórmulas científicas; a religiosa trabalha com os símbolos religiosos; a artística trabalha com as cores e as formas (pintura, escultura), bem como melodias (música). Dentre todos os signos, os verbais são os únicos que têm onipresença nessas esferas, e além delas - nas relações de produção, nas interações sociais da vida cotidiana. O caráter especial da linguagem verbal, segundo o filósofo russo, justifica a necessidade de um estudo aprofundado acerca da mesma. Voltaremos a isso.

Para Voloshinov (1979, p.19), o signo ideológico é "um fragmento material" da realidade, isto é, possui “[...] uma encarnação material, seja como som, como massa física, como cor, como movimento do corpo ou como outra coisa qualquer. Nesse sentido, a realidade do signo é totalmente objetiva." Sendo assim, as ideologias não se situam no domínio da consciência, mas na realidade objetiva dos signos e das formas da interação sócio-verbal. As ideologias têm um caráter material e seus produtos, os signos, são também materiais. Além disso, a ideologia é social, já que os seus elementos constitutivos, os signos, são sociais: "[...] não basta colocar face a face dois homo sapiens quaisquer para que os signos se constituam. É fundamental que esses dois indivíduos estejam socialmente organizados, que formem um grupo (uma unidade social): só assim um sistema de signos pode constituir-se." (VOLOSHINOV, 1979, p.21). Trata-se de uma objeção a uma concepção idealista e individualista da ideologia, segundo a qual esta é produzida por uma consciência individual sem relações com as condições materiais de existência. Por sua concepção do caráter material da ideologia e dos objetos ideológicos, Voloshinov se distancia das proposições de Bukharin, por exemplo, para quem os produtos ideológicos, ainda que derivados de uma realidade material, são concebidos como "produtos espirituais".

Contudo o que caracteriza o signo mais fortemente, segundo Voloshinov (1979, p.17), é que "[...] ele também reflete e refrata uma outra realidade que lhe é exterior", ou seja, remete para algo que está fora de si mesmo, e possui um significado. Ao mesmo tempo em que é elemento material da realidade, o signo também remete para outros elementos além dele. No processo de reflexo e refração da realidade, o signo "[...] pode distorcer essa realidade, ser-lhe fiel, ou apreendê-la de um ponto de vista específico." (VOLOSHINOV, 1979, p.18). Parece haver, em Voloshinov, três fatores determinantes do caráter refrativo dos signos. Trataremos desses fatores logo a seguir.

Como dissemos há pouco, Voloshinov (1979, p.22) defende que a palavra deve ser colocada "em primeiro plano no estudo das ideologias". Isso se justifica 
pelo fato de que o estudo da palavra permite observar as transformações que, originadas na infraestrutura, chegam às superestruturas e aí exercem efeitos. A tese do autor é que a palavra é:

[...] o indicador mais sensível de todas as transformações sociais [...]. A palavra constitui o meio no qual se produzem lentas acumulações quantitativas de mudanças [...]. A palavra é capaz de registrar as fases transitórias mais ínfimas, mais efêmeras das mudanças sociais. (VOLOSHINOV, 1979, p.27, grifo nosso).

Por isso, Voloshinov (1979) dedica especial atenção à descrição do signo verbal em suas características específicas. Em primeiro lugar, porque é elemento constitutivo de todas as esferas ideológicas, sendo um signo "neutro" (no sentido de que não tem nenhuma função ideológica específica, podendo "[...] preencher qualquer espécie de função ideológica: estética, científica, moral, religiosa." (VOLOSHINOV, 1979, p.22-23); ou seja, a palavra está presente em todas as esferas da criação ideológica, enquanto certos signos só podem pertencer a certa esfera. ${ }^{3}$ Em segundo, porque está em todos os domínios das relações sociais, principalmente o da comunicação na vida ordinária (onde impera a ideologia do cotidiano), da qual é o material privilegiado. Em terceiro, porque é "o material semiótico da vida interior, da consciência", é o material do discurso interior.

Conforme dito anteriormente, a grande contribuição de Voloshinov para o estudo da ideologia no campo marxista é a sua tese do caráter semiótico (ou semiológico) da ideologia, ou seja, o fato de ela ser constituída de signos. A ideologia nunca fora pensada desse ponto de vista na tradição marxista. Mas quando formula que esses signos refletem e refratam o real, outra contribuição de Voloshinov para o campo, ele toca num problema marxista clássico - o da natureza da ideologia enquanto sistema de representações do real e num problema a ele associado pela maioria dos marxistas posteriores a Marx e Engels, o do caráter de falsidade/distorção dessas representações. É isso que discutiremos a seguir.

\section{Ideologia enquanto sistema de representações do real}

Voloshinov apresenta algumas definições de ideologia no conjunto de seus trabalhos, todas elas complementares e mutuamente esclarecedoras. Uma dessas definições é a apresentada numa nota do ensaio "O que é a linguagem?", de 1930: "[... tutto l'insieme dei riflessi e dele interpretazioni dela realtà sociale e naturale

\footnotetext{
3 Veja-se que, para Voloshinov, neutralidade não quer dizer ausência de traços ideológicos. Consideramos que a terminologia usada por Ponzio (2008) é mais adequada para desfazer uma possível ambiguidade da palavra neutralidade. Para ele, o signo verbal possui uma flexibilidade ideológica.
} 
che avvengono nel cervello dell'uomo e sono expresse e fissate per mezzo di parole, disegni, schizzi o altre forme segniche." (VOLOSHINOV, 1980, p.249). ${ }^{4}$

Conforme Ponzio (2008), essa definição de ideologia segue aquela avançada por Marx, no que tange a sua natureza de representações, reflexos do real, mas difere da mesma por não atribuir às representações ideológicas o caráter de falsidade, de mistificação, de distorção do real tal como o faz o pensador alemão.

Mas essa definição, para Ponzio (2008, p.114), é "[...] muito sintética e superficial com relação ao uso que o termo [ideologia] adquire.", devendo ser completada com base nos outros trabalhos de Voloshinov e do Círculo.

Para o autor italiano, ideologia, no contexto do grupo bakhtiniano, pode designar tanto representações falsas, ilusões, quanto representações verdadeiras, objetivas - posição que seguimos e corroboramos. A seguinte passagem de Voloshinov (1979, p.33, grifo nosso) aponta para o caráter deformador da ideologia:

[...] na ideologia dominante estabelecida, o signo ideológico é sempre um pouco reacionário e tenta, por assim dizer, estabilizar o estágio anterior da corrente dialética da evolução social e valorizar a verdade de ontem como sendo válida para hoje em dia. Donde o caráter refrativo e deformatório do signo ideológico nos limites da ideologia dominante. ${ }^{5}$

Ponzio (2008) conclui que, para Voloshinov, o falseamento e a verdade das representações ideológicas seriam determinados pela perspectiva de classe - a ideologia da classe dominante teria caráter predominantemente falseado, porque a classe dominante é interessada em defender seus privilégios e impedir a transformação da sociedade (nisso, a ideologia dominante seria mais ou menos deliberada, instrumental), enquanto a ideologia da classe dominada estaria mais próxima da verdade, porque a classe dominada está interessada em mudar a realidade, em questionar o que é apresentado como natural e óbvio, sempre a partir de uma análise da realidade, com base em sua práxis, como critério de verificação.

Voloshinov entende que todas as classes são capazes de produzir suas ideologias, representando suas condições de existência materiais, e que essas ideologias travam lutas num processo dialético. As perspectivas de classe entram

\footnotetext{
4 " $[. .$.$] todo o conjunto dos reflexos e das interpretações da realidade social e natural que ocorre no cérebro do$ homem e se expressa e fixa por meio das palavras, desenhos, esquemas ou outras formas sígnicas."

5 Vale ressaltar que, segundo Vianna (2010), Voloshinov, ao formular essa posição, segue e desenvolve no que respeita à linguagem uma formulação de Marx e Engels (1976), presente na Ideologia alemã, acerca da ideologia, qual seja: a ideologia dominante, que é a da classe dominante, expressa as ideias e os interesses dessa classe dominante de uma forma que essas ideias e interesses são apresentados como tendo um caráter de universalidade e não de particularidade.
} 
em luta no campo ideológico por meio dos signos que são constituídos de índices sociais de valor impressos neles por essas classes. No entanto, para Voloshinov, essa luta não é travada em igualdade de condições: a ideologia dominante tenta apagar índices sociais de valor heterogêneos, visando a estabilizar aqueles que respondem a seus interesses.

Essa posição estaria presente na argumentação de Voloshinov no texto "A palavra e sua função social", ${ }^{6}$ que Faraco (2006, p.69), assim resume:

[...] na linguagem de cada classe há sempre um grau particular de correspondência entre o verbal e a realidade objetiva, cabendo ao proletariado o ponto de vista que mais intimamente se aproxima da 'lógica objetiva da realidade'. Quer dizer: Voloshinov assume que a linguagem do proletariado também refrata o mundo (não é, portanto, integralmente não refratada), mas a refração é menor do que aquela que ocorre em outras classes sociais.

Em suma: pode-se afirmar que Voloshinov segue a concepção de Marx acerca da ideologia como tendo um caráter de distorção, ilusão, deformação, ainda que o termo ideologia, no autor russo, não tenha apenas esse sentido, podendo designar também representações verdadeiras/adequadas do real.

Vê-se que, em suas formulações, Voloshinov atribui o caráter distorcido das representações ideológicas a dois fatores já apontados por Marx, e corroborados pela tradição marxista. O primeiro fator seria a existência de esferas ou ramos da ideologia que tratam apenas de certos aspectos da realidade, refletindo-os e refratando-os a seu modo. Segundo Voloshinov (1979, p.19): "Cada campo de criatividade ideológica tem seu próprio modo de orientação para a realidade e refrata a realidade a sua própria maneira. Cada campo dispõe de sua própria função no conjunto da vida social."

Essa passagem do autor russo segue de perto o que dizem Marx e Engels em A ideologia alemã, quando sustentam que um dos fatores do falseamento da ideologia é a divisão do trabalho, que separa o trabalho manual e o intelectual, e a "subdivisão ideológica" no interior deste, que diferencia e autonomiza os diferentes profissionais da ideologia, isto é, os juristas, os políticos, os moralistas, os homens de religião etc.: "É então necessário considerar os sonhos dogmáticos e as ideias extravagantes desses sujeitos como uma ilusão que se explica muito simplesmente pela sua posição prática na vida, a sua profissão e a divisão do trabalho." (MARX; ENGELS, 1976, p.60). Explicam os autores que "[...] cada qual considera sua profissão como verdadeira. Sobre a ligação de seu trabalho com a realidade iludem-se necessariamente dada a natureza desse trabalho. Em

Os artigos de Voloshinov, "O que é a linguagem?" e "A palavra e sua função social”, ambos de 1930, citados aqui indiretamente, podem ser encontrados em Voloshinov (1980). 
jurisprudência, em política, etc., essas relações transformam-se - na consciência - em conceitos." (MARX; ENGELS, 1976, p.98).

O segundo fator seria a existência de perspectivas de classe nas ideologias, porque há classes e há interesses de classe representados nas ideologias. Conforme Marx (1985a, p.17):

\begin{abstract}
A burguesia tinha conquistado poder político na França e Inglaterra. A partir de então, a luta de classes assumiu, na teoria e na prática, formas cada vez mais explícitas e ameaçadoras. Ela fez soar o sino fúnebre da economia científica burguesa. Já não se tratava de saber se este ou aquele teorema era ou não verdadeiro, mas se, para o capital, ele era útil ou prejudicial, cômodo ou incômodo, subversivo ou não. No lugar da pesquisa desinteressada entrou a espadacharia mercenária, no lugar da pesquisa científica imparcial entrou a má consciência e a má intenção da apologética.
\end{abstract}

A partir de sua perspectiva particular, Voloshinov (1979) afirma que os signos são a arena da luta de classes, uma vez que estes são constituídos por índices sociais de valor impressos neles pelas classes em luta.

Pode-se dizer, entretanto, que, no pensamento do autor russo, esses fatores não seriam os únicos a explicar as razões do falseamento ou do caráter ilusório das representações ideológicas - haveria também um terceiro fator, pensado originalmente por ele, a partir de sua perspectiva semiológica: a natureza refrativa do signo, que mencionamos mais acima. Como os signos não apenas refletem, mas também refratam o real, distorcendo-o ou mesmo deformando-o, e como nosso acesso ao real é sempre mediado pelos signos, eles podem constituir fator determinante do falseamento das ideologias. ${ }^{7}$ Essa tese é uma contribuição original de Voloshinov ao problema em vista. Em outras palavras, poderíamos dizer que Voloshinov aponta para a presença de um fator semiológico, ao lado do fator sociológico, determinando a distorção/deformação das representações da ideologia.

Além disso, Voloshinov apresenta, em suas considerações, três fatores determinantes da refração do ser pelo signo ideológico. O primeiro seria o fato de os signos serem produzidos no interior de uma determinada esfera ideológica. O segundo seria o fato de haver um "[...] confronto de interesses sociais nos limites de uma só e mesma comunidade semiótica, ou seja: a luta de classes." (VOLOSHINOV, 1979, p.32, grifo nosso), o que determina que cada signo seja atravessado por "índices sociais de valor" impressos pelas classes sociais, índices esses contraditórios. O terceiro fator do caráter refrativo dos signos seria a sua

Certamente, não defendemos aqui que os signos são, para Voloshinov, fator necessariamente determinante da deformação das representações ideológicas, já que estas podem ser também verdadeiras, justas e adequadas. 
própria historicidade. Zandwais (2005) afirma que os signos, que representam a realidade, adquirem historicamente valores simbólicos múltiplos - adquirem, em contextos distintos, valores simbólicos/sentidos diversos - o que os torna polissêmicos e incompletos. Conforme Miotello (2005, p.172), a posição de Voloshinov (e do Círculo de Bakhtin) é que: "Vozes diversas ecoam nos signos e neles coexistem contradições ideológico-sociais entre o passado e o presente, entre as várias épocas do passado, entre os vários grupos do presente, entre os futuros possíveis e contraditórios."

Em face dessas considerações, entendemos que, no pensamento deVoloshinov, o principal determinante do caráter deformador e ilusório das representações ideológicas é mesmo a natureza refrativa dos signos. E é porque os signos refletem e refratam o real que as representações do real não são cópias, imitações perfeitas, mas distorcidas ou até mesmo deformadas. Certamente, o fator classe social está fortemente implicado nessa deformação, mas ele está mais ligado ao grau de refração do signo. Retomaremos esse ponto adiante.

Comentamos anteriormente que se podem identificar nas formulações de Voloshinov acerca da ideologia algumas teses de Marx, corroboradas pela tradição marxista, como o fato de ela ser dividida em esferas e de apresentar interesses ou perspectivas de classe. Comentamos também que Voloshinov, avançando na reflexão sobre o problema, apresenta outras duas teses originais: a natureza semiológica da ideologia e o caráter refrativo dos signos ideológicos (dentre os quais, os verbais). Defendemos que, para Voloshinov, as ideologias podem ter caráter falseado, ilusório, deformado, devido a essas características, ainda que elas possam também ter caráter de verdade e adequação.

Mas existe no pensamento de Marx um outro fator que determina o caráter falseado da ideologia (esse fator parece não estar presente no pensamento de Voloshinov, nem no de seus contemporâneos russos) - o próprio modo de funcionamento do real, a sua opacidade. A ausência dessa concepção do real em Voloshinov é o que, a nosso ver, implica a proposição de uma definição de ideologia que não a opõe à verdade. Vejamos.

Marx (1985a, 1985b), em O Capital, a partir da análise do fetichismo da mercadoria, lança a tese de que a realidade material, nas sociedades capitalistas, não é transparente aos sujeitos ou à consciência, pois ela se apresenta sempre através de formas manifestas, aparentes, que tornam invisíveis as formas essenciais (a realidade se apresenta sempre se automistificando). Há aqui uma concepção do funcionamento do real próxima à da física - o movimento dos astros apresenta-se aos sujeitos sob uma forma aparente em que a Terra está parada e o Sol gira em torno dela; é somente essa realidade que os sujeitos percebem através da visão, que lhes mostra que o Sol nasce no leste e se põe no oeste. Mas a ciência física deve ser capaz de mostrar o movimento real invisível por trás do 
movimento aparente - a Terra é que gira em torno do Sol e, ainda, de si mesma - e de explicar os motivos da ilusão ótica.

Sendo assim, em O Capital, Marx passa a postular que o próprio modo de funcionamento do real é que é responsável pela distorção das representações acerca dele, e não mais a consciência dos sujeitos, como proposto nas obras anteriores. Para Rouanet (1985), Marx, em suas primeiras obras, não problematizara o real: a desmistificação das representações ideológicas seria possível através da observação da realidade que não seria afetada pelo problema da opacidade; já em suas últimas obras, o real não poderia ser fator de desmistificação, pois ele mesmo se apresenta mistificado, não sendo transparente. Assim, a análise da realidade material não seria suficiente para desfazer, dissolver a ilusão, pois ela "deixou de ser crítica, e passou a ser mistificada" (ROUANET, 1985, p.102, grifo do autor).

Agora, para Marx, as ideologias não são mais um simples epifenômeno da realidade material, mas sim "uma forma de expressão imediata do movimento aparente" do real (ROUANET, 1985, p.105). As ideologias ficam justamente no nível do movimento aparente do real, nunca chegam ao seu movimento essencial, que é prerrogativa da ciência. A consciência espontânea dos agentes (na qual se produzem as representações ideológicas) seria uma falsa consciência, pois toma o movimento aparente perceptível aos sentidos, imediatos, visíveis, como se fossem o movimento real, vendo nas formas manifestas as formas essenciais. Somente a ciência da história poderia dar uma explicação do verdadeiro funcionamento da realidade material, e das causas da ilusão. A ciência faria uma análise dessa realidade, mas uma análise que, ultrapassando as evidências primeiras, as formas aparentes, chegaria às formas essenciais.

No pensamento de Voloshinov, como dissemos, não parece fazer-se presente essa última tese de Marx acerca das causas da ideologia como falseamento, ilusão - a do real opaco, mistificado em seu próprio funcionamento. Por outro lado, a própria tese da necessidade do caráter falseado das ideologias que é regra em Marx, ou seja, está presente ao longo de todas as suas obras, não é seguida radicalmente por Voloshinov. Para Marx, as ideologias são sempre falseamentos, erros, e nunca verdade - o verdadeiro conhecimento do real só se dá a partir da ciência, que se distingue qualitativamente das ideologias. Já para Voloshinov, contrariamente, as ideologias podem ser tanto verdade quanto ilusão.

Certamente, Voloshinov não concebe o real como transparente. No entanto, para ele, a opacidade não é derivada do próprio modo de funcionamento do real, mas é devida a um elemento que a causa, nesse caso, o signo. Zandwais (2005, p.91), afirma que, para Voloshinov, "[...] a ordem do real não é transparente, não é evidente e, tampouco, passível de ser apreendida em sua totalidade." visto que os signos que a representam adquirem historicamente valores simbólicos múltiplos, o que os torna polissêmicos. 
Voloshinov (1979, p.33) assim aborda a propriedade do signo de conter valores e sentidos múltiplos: "Na realidade, todo signo ideológico vivo tem, como Jano, duas faces. Toda crítica viva pode tornar-se elogio, toda verdade viva não pode deixar de parecer para alguns a maior das mentiras." Para o autor, essa propriedade caracteriza a existência de uma "dialética interna do signo"; esta última liga-se ao processo histórico de evolução do signo, isto é, à historicidade do signo. No entanto, tal dialética não seria evidente para os sujeitos, uma vez que a ideologia dominante "[...] tenta, por assim dizer, estabilizar o estágio anterior da corrente dialética da evolução social e valorizar a verdade de ontem como sendo válida hoje em dia." (VOLOSHINOV, 1979, p.33, grifo nosso).

Ou seja, a opacidade do real se deve à refração dos signos e aos valores simbólicos que eles adquirem historicamente; é uma opacidade determinada pela linguagem. Mas, em última instância, a opacidade do real deriva da existência das classes, já que no signo se trava a luta de classes. Em suma: a questão do real como mistificado em si mesmo está ausente da problemática de Voloshinov.

Tudo isso leva-nos a examinar como Voloshinov concebe a possibilidade de as ideologias darem representações verdadeiras do real. Se as representações ideológicas podem ser falsas ou verdadeiras, como distingui-las? A questão da produção da verdade passaria pelo problema essencial da refração do ser pelo signo, que já comentamos anteriormente: o signo pode apreender de um ponto de vista específico e parcial a realidade, e distorcê-la ou ser-lhe fiel. Na medida em que pouco distorce a realidade, sendo-lhe mais fiel, o signo é adequado à realidade e não produz ilusão. Se há maior grau de refração, há menos verdade; se há menor grau de refração, há mais conformidade com o real e mais verdade. A tese de Voloshinov, apresentada por Faraco (2006, p.69), de que “[...] na linguagem de cada classe há sempre um grau particular de correspondência entre o verbal e a realidade objetiva, cabendo ao proletariado o ponto de vista que mais intimamente se aproxima da 'lógica objetiva da realidade'.", leva-nos a destacar duas posições de Voloshinov sobre o problema da produção de representações verdadeiras do real.

A primeira delas é que a classe proletária, revolucionária, teria uma "capacidade cognoscitiva", por assim dizer, superior a da classe dominante, uma vez que o grau de refração dos seus signos ideológicos é menor. As ideologias que representassem o ponto de vista dessa classe estariam mais próximas da realidade, sendo, portanto, verdadeiras. A segunda é que a realidade, em Voloshinov, é crítica, conforme o sentido dado a esse termo por Rouanet (1985) - ela é critério de verificação. Quanto a esse ponto, Voloshinov parece estar mais próximo das primeiras formulações de Marx acerca do real, em que é ele fator de verificação, tem aspecto crítico, ao invés de ser ele mesmo uma das causas da ilusão. O real, 
para o autor russo, em si mesmo não seria opaco; sua opacidade derivaria da mediação dos signos (que refletem/refratam o real).

Com base nessas considerações, entende-se porque, para Voloshinov, não faz sentido postular uma distinção entre ciência e ideologia: as ideologias podem ser verdadeiras ou falseadas. Entende-se também por que a ciência é concebida por Voloshinov como uma das esferas da criatividade ideológica. Conforme essa posição, poderia haver uma ciência verdadeira (a ciência proletária) e uma ciência falsa (a ciência burguesa), uma moral verdadeira e uma moral falsa e assim sucessivamente.

Sendo assim, não se aplica a Voloshinov a tese da oposição entre ciência e ideologia, radical em Marx, para quem: " [...] toda ciência seria supérflua se a forma de manifestação e a essência das coisas coincidissem imediatamente [...]" (MARX, 1985b, p.271). Como se vê, o autor alemão fundamenta a necessidade da ciência na tese da opacidade do real: pelo fato de o real se mostrar em sua forma aparente e as representações ideológicas representarem justamente esse movimento aparente, surge a necessidade da ciência, como o campo que pode chegar ao movimento essencial do real e aos motivos da ilusão. A percepção imediata e espontânea só capta a aparência do funcionamento do real.

Voloshinov não supõe uma oposição nem mesmo uma distinção entre ciência e ideologia. A ciência é, para Voloshinov, uma esfera da criação ideológica e, portanto, as duas não possuiriam uma diferença qualitativa. As formulações de Voloshinov não permitem, portanto, pensar a distinção entre ciência e ideologia, e nem a necessidade da ciência - se a ideologia pode dar uma representação verdadeira, adequada do real, em que ela se distingue da ciência, qual a necessidade desta última?

A partir dessas considerações, poderíamos discutir algumas críticas de Faraco (2006) a Voloshinov. A primeira crítica seria que Voloshinov não explicaria a causa dos graus de refração do ser pelo signo, ou ainda não esclareceria "como estabelecer estes graus de refração" (FARACO, 2006, p.69). Poderíamos objetar que a causa é, sim, apontada pelo autor russo e seria o interesse de classe: enquanto a classe dominante precisa, para assegurar sua situação de classe dominante, manter a estrutura social e os sentidos estabilizados, a classe dominada tem interesse em criticar e discutir o que se apresenta como natural e óbvio no contexto daquela ideologia, a fim de mudar suas condições de vida, e faz essa crítica e esse questionamento com base em sua práxis.

A segunda crítica de Faraco (2006, p.69) assim se coloca:

Fica irresolvida, em seus textos [de Voloshinov], a conjunção da teoria da refração (todo e qualquer signo refrata necessariamente o mundo) - que implica a existência simultânea de 'várias verdades sociais' - e 
uma teoria da divisão da sociedade em classes - que explicitamente atribui a verdade a uma das classes (o proletariado).

Aqui teríamos de discordar da leitura de Faraco de que a natureza refrativa do signo teria como consequência a "existência simultânea de várias verdades sociais". A nosso ver, com base em tudo que expusemos, a posição de Voloshinov é que uma sociedade se marca pela simultaneidade de verdades e de ilusões, distorções, falseamentos que estão em conflito. Seguimos Ponzio (2008, p.116), quando este afirma que, para Voloshinov, "[...] existem ideologias científicas e formas de falsa consciência; existem deformações (mais ou menos deliberadas) de classes da realidade." Além disso, os diferentes pontos de vista não estariam num mesmo plano, mas admitiriam valores diferentes - verdade ou ilusão, deformação etc. - os quais seriam passíveis de comprovação ou de crítica, o que permitiria o desenvolvimento do conhecimento humano.

A última crítica de Faraco a Voloshinov aponta que o autor não explicaria se numa sociedade sem classes deixaria de haver a refração dos signos: "[...] fica bastante clara sua dificuldade em juntar as duas teorias, em harmonizar a (eterna) refração com a redenção da sociedade sem classes." (FARACO, 2006, p.69). A nosso ver, se levamos em conta que um dos fatores da refração do signo, além da existência das classes, é a sua historicidade, como comentamos acima, Voloshinov dá, sim, uma resposta à questão - numa sociedade sem classes, a refração continuaria a existir, porque o signo sempre será histórico, contendo índices de valor que ele adquiriu ao longo de sua existência, e sendo objeto de luta entre sentidos atuais e sentidos passados, que lhe dariam seu caráter refrativo.

\section{Considerações finais}

Ao final de nossa reflexão, esperamos ter evidenciado que o conceito de ideologia é constitutivo da filosofia da linguagem de Voloshinov. Ele está articulado a todos os problemas particulares dessa filosofia, tais como: a comunicação social, a interação verbal, os gêneros discursivos (do cotidiano e das esferas sistematizadas), os signos ideológicos e sua constituição, as mudanças da língua e da linguagem.

Nossa perspectiva é que essa reflexão possa chamar a atenção para a importância de uma recuperação desse conceito e de sua articulação com outros formulados ao longo da trajetória teórica do Círculo de Bakhtin, quando está em questão a análise de objetos os mais diversos, tais como palavras, enunciados, textos e até imagens. Entendemos que a articulação do conceito de ideologia com o de diálogo, o conceito bakhtiniano mais mobilizado na atualidade, pode engendrar resultados valiosos sobre a função e o funcionamento do discurso 
em nossa sociedade. O dialogismo não é marca apenas das relações entre palavras, enunciados, textos, imagens, mas também das relações entre as ideologias, as vozes sociais, que atravessam constitutivamente esses objetos linguístico-verbais.

Os estudos do discurso de orientação bakhtiniana só têm a ganhar se não perderem de vista essa relação íntima entre dialogismo e ideologia. O tratamento das relações dialógicas em si mesmas, no qual elas não sejam articuladas a outros conceitos do grupo bakhtiniano, no qual a perspectiva sociológica que rege essas relações fique apagada, pode conduzir a uma redução do diálogo a uma simples intertextualidade ou intericonicidade.

NARZETTI, C. V. Volochinov's philosophy of language and the concept of ideology. Alfa, São Paulo, v.57, n.2, p.367-388, 2013.

- ABSTRACT: This work deals with the conception of ideology that crosses and constitutes V. Volochinov's philosophy of language. This author was one of the members of Bakhtin Circle. This study aims to shed new light on some complex, delicate points of the global conception of ideology supported by Volochinov, about which the scholars of the Russian group have not yet reached a definition or a consensus. The exposition is organized around three points: 1) ideology as a structural element of society; 2) ideology as a field of signs; 3) ideology as representation of reality. The discussion focuses on the formulations in which Voloshinov advances based on what their theoretical sources already had proposed, especially with regard to the articulation of ideology with language. It is hoped that this work can call attention to the importance not only of the resumption of the concept, but also of its relationship with other concepts of the Bakhtin Circle, such as dialogue. This articulation could lead to an increasing enrichment of the researches on discourse analysis that follow Bakhtin's tradition.

- KEYWORDS: Ideology. Volochinov. Philosophy of language. Bakhtin Circle.

\section{REFERENCIAS}

BUKHARIN, N. Tratado de materialismo histórico. Tradução de Edgar Carone. Rio de Janeiro: Laemmert, 1970.

CANGUILHEM, G. O objeto da história das ciências. Tempo Brasileiro, Rio de Janeiro, n.28, p.7-21, jan./mar.1972.

CLARK, K.; HOLQUIST, M. Mikhail Bakhtin. Tradução de J. Guinsburg. São Paulo: Perspectiva, 1998.

FARACO, C. A. Linguagem e diálogo: as idéias linguísticas do círculo de Bakhtin. 2.ed. Curitiba: Criar, 2006.

GRILLO, S. V. de C. Gêneros primários e gêneros secundários no círculo de Bakhtin: implicações para a divulgação científica. Alfa, São Paulo, v.52, n.1, p.57-79, 2008. Disponível em: <www.alfa.ibilce.unesp.br/download/v52-1/04-Grillo.pdf>. Acesso em: 10 jul. 2008. 
MARX, K. O capital: crítica da economia política. Tradução de Regis Barbosa e Flávio R. Kothe. São Paulo: Nova Cultural, 1985a. v.1. t. I.

O capital: crítica da economia política. Tradução de Regis Barbosa e Flávio R. Kothe. São Paulo: Nova Cultural, 1985b. v.3. t. II.

MARX, K.; ENGELS, F. A ideologia alemã. Tradução de Conceição Jardim e Eduardo Nogueira. Lisboa: Presença; São Paulo: Martins Fontes, 1976. v.1.

MIOTELLO, V. Ideologia. In: BRAIT, B. (Org). Bakhtin: conceitos-chave. 2.ed. São Paulo: Contexto, 2005. p.167-176.

PLEKHANOV, G. Os princípios fundamentais do marxismo. Tradução de Sônia Rangel. São Paulo: HUCITEC, 1978.

PONZIO, A. A revolução bakhtiniana. Tradução de Valdemir Miotello et al. São Paulo: Contexto, 2008.

ROUANET, S. P. A razão cativa: as ilusões da consciência: de Platão a Freud. São Paulo: Brasiliense, 1985.

TCHOUGOUNNIKOV, S. O círculo de Bakhtin e o marxismo soviético: uma "aliança ambivalente". Conexão Letras, Porto Alegre, v.3, p.1-15, 2007. Disponível em: <http://www.msmidia.com/conexao/3/cap3.pdf>. Acesso em: 21 ago. 2008.

TIHANOV, G. The master and the slave: Lukács, Bakhtin, and the ideas of their time. Oxford: Oxford University Press, 2000.

VIANNA, R. Marxismo e filosofia da linguagem à luz d'A ideologia alemã. Bakhtiniana, São Paulo, v.1, n.3, p.29-41, 2010. Disponível em: <http://revistas. pucsp.br/index.php/bakhtiniana/article/view/3368/2238>. Acesso em: $11 \mathrm{fev}$. 2011.

VOLOSHINOV, V. N. Che cos'è il linguaggio? In: VOLOŠINOV, V. N. Il linguaggio come pratica sociale. Traduzione di Rita Bruzzese e Nicoletta Marcialis. Bari: Dedalo, 1980. p.61-94.

VOLOSHINOV, V. [BAKHTIN, M.]. Marxismo e filosofia da linguagem: problemas fundamentais do método sociológico na ciência da linguagem. Tradução de Michel Lahud e Yara Frateschi. São Paulo: HUCITEC, 1979.

ZANDWAIS, A. Relações entre a filosofia da práxis e a filosofia da linguagem sob a ótica de Mikhail Bakhtin: um discurso fundador. In: (Org.). Mikhail Bakhtin: contribuições para a filosofia da linguagem e estudos discursivos. Porto Alegre: Sagra Luzzatto, 2005. p.83-100.

Recebido em outubro de 2011

Aprovado em dezembro de 2012 